\title{
The More We Tinder: Subjects, Selves and Society
}

\author{
Johanna Degen ${ }^{1}$ (D) - Andrea Kleeberg-Niepage ${ }^{1}$ (D) \\ Received: 3 January 2020 / Revised: 29 June 2020 / Accepted: 17 July 2020/ \\ Published online: 11 August 2020 \\ (C) The Author(s) 2020
}

\begin{abstract}
Mobile online dating is currently a widespread and important phenomenon in many peoples' daily lives. Digital applications like Tinder enable users to get in contact with numerous possible partners quickly and with minimal effort often basing their decision on pictures. Research related to mobile online dating so far has focused mostly on users' specific traits or on their motives to use such applications. But which role does mobile online dating play in peoples' lives? What does it mean to them? Which desires, emotions and expectations are involved? How does the use of the application influence peoples' daily activities and how do they relate to this impact? To answer these questions, we (a) reconstructed the architecture of Tinder to understand the characteristics of its functions for the way it is used and the respective consequences, (b) replicated the Tinder Motives Scale (Timmermans \& De Caluwe, Comput. Hum. Behav., 70, S. 341-350, 2017)extended by social and demographic variables and (c) analyzed qualitative interviews with Tinder users about their experiences, their usage and its impact on emotions, thoughts and behaviour. In this article, we show the complexity of mobile online dating beyond presumptions and stereotypes and reveal its inherent economic logic (Weigel, 2018) and acceleration dynamics (Rosa, 2013). Furthermore, we reference people's narrations and rationalizations to a specific discourse of the self which shapes subjects' private concept of the self in a particular - liberal and economic - logic (Gergen, 1991, Rose, 1989) and reflect on the subjects' scopes for action and meaning making.
\end{abstract}

Keywords Acceleration · Discourse of the self $\cdot$ Marketization $\cdot$ Mobile online dating $\cdot$ Scopes for action $\cdot$ Tinder

Johanna Degen

johanna.degen@uni-flensburg.de

Andrea Kleeberg-Niepage

andrea.kleeberg-niepage@uni-flensburg.de

1 Department of Psychology, Europa-University Flensburg, Auf dem Campus 1, 24943 Flensburg, Germany 


\section{Researching Mobile Online Dating: Theoretical and Empirical Framework}

The use of dating applications on mobile devices has become a mass phenomenon-where Tinder is one of the leading providers of so-called easy access dating, location-based dating or micro dating with mainly picture-based profiles and high-speed operation - enabling quick decisions based on very little information. These apps have millions of active daily users worldwide. Along with increasing social acceptance, Smith and Duggan (2013) found that $53 \%$ of Internet users agree with the statement that mobile 'online dating allows people to find a better match for themselves because they can get to know a lot more people' (n.p.). At the same time, the opinion that 'online dating users are desperate' decreased significantly (Smith \& Duggan, 2013, n.p.).

Creating a Tinder profile comes with the minimum requirements to disclose one's location, age, gender and sexual orientation and usually show at least one picture. The pictures become the main content by which users make decisions about suggested matches. By swiping either to the right to confirm interest or swiping left to reject the suggestion, a rather quick and light process of 'swiping along' is established. Being a mobile application, it is possible to be continuously available and active and to have permanent access to countless opportunities, which has fundamentally changed the modus of searching for a partner compared with dating applications for desktop computers, not to mention former analogue dating (services). Gatter and Hodkins (2016) compared online dating agencies users and app users and found no significant difference in regard to sociability, self-esteem and sexual permissiveness. One can still assume that the changing context of dating should come with important implications for the daily practice of looking for a partner, handling one's profile and dating itself.

The research conducted so far gives some, sometimes contradictory, insights into the phenomenon of online dating apps. Research has for example focused on motives to use such apps. Carpenter and McEwan (2016) claim that user's motivation is mainly entertainment or finding sexual partners, suggesting a classification of these apps in general as 'casual sex apps' (n.p.). This seems to be an exception and a contradiction to other research which rejects the public reputation of these apps as being hook-up apps. Ward's (2016) results show for example that main motives are namely entertainment, ego boost and relationship seeking. Sumter, Vandenbosch and Ligtenberg (2016) and foremost Timmermans and De Caluwé (2017) show even more differentiated motives. They developed the validated Tinder Motives Scale (TMS) based on qualitative studies showing a complex picture of 13 motives. Here, the interest to increase sexual experience appears in place 11 of 13 motives, with pastime and curiosity as the main named motives, along with others like practicing flirting skills or getting over an ex.

Other research focusses on dispositions like sociability, impulsiveness and interest in varied sexual partners (Carpenter \& McEwan, 2016), or on personality traits like having higher scores in the dark triad, i.e. Machiavellianism, narcissism and psychopathy (Sevi, 2019) or in regard to self-esteem and body image (Strubel \& Petrie, 2017). In contrast to the findings of Gatter and Hodkinson (2016), Strubel and Petrie (2017) demonstrate findings that, just like public presumptions, especially self-esteem of male users is lower than the control group of non-users and that for both male and female users, body image is significantly more negative towards themselves, counting for body shame and satisfaction with face and body.

Research about the actual profiles and self-presentation conducted by Duguay (2015) was on the degree of users being authentic or optimizing their profile. She argues that Tinder actually is built in a way to secure authenticity due to the connection to Facebook and aims to 
authenticate that profiles are most likely connected to a real person by showing to a certain degree the digital real life (for instance connecting with Instagram). Ward (2016) puts the question of authenticity in the context of Goffman's theory of impression management. The first impression here is relocated from a former physical meeting, where one might optimize by putting on perfume and shave but still appear as a whole person, to a digital profile, mostly showing one picture and the subsequent dichotomous reaction (like or dislike). Ward (2017) shows that this leads to a careful and serious process of constructing a desired impression of how others should see one which is then continuously maintained in an aim to combine an idealized yet authentic self-presentation. Hance, Blackhart, and Dew (2018) found out that rejection sensitivity and online dating are correlated. They show that rejection-sensitive individuals (users) feel they can more easily represent their so-called true selves in online environments. These findings are consistent with the findings of Fitzpatrick, Birnholtz and Brubaker (2015) who frame disclosure with the question of impact and varieties of location norms, body image, race relations and social stigma. They show that disclosure of the face is dependent on BMI, race, age and relationship status. Whether or not the motive is short-term incentives or a lifetime relationship, people tend to 'self-present in a way that makes you attractive to others' (Ward, 2016, p. 82). In this context, the creation of a profile is an important matter to increase chances for a relationship or rather relationship opportunities. As a result, users tend to choose either pictures they like a lot themselves or that have been validated from other social media platforms, such as having many likes on Facebook or other forms of friends' advice (Ward, 2016); it is a process that is taken seriously and is categorized as significant.

A few studies confirm the stereotypical thinking, for example, that men rather tend to permissiveness and willingness for short-term incentives (Sevi, Aral \& Eskenazi, 2017) and that there occur differences in user habits in regard to gender, where men tend to be less selective as the match rate differs significantly (Tyson et al., 2016). Besides, Sedgeweck, Flath and Elias (2017) show stereotypical gender differences occur regarding the self-presentation in form of angle - men tend to take the picture from below to position as powerful; females from above for childlike characteristics and softness.

Even though this research gives several insights, it leaves at least three perspectives rather unattended: First, how the specific daily use or rather using habits of the apps functions and its digital architecture affect significantly subjects' perceptions with regard to the dynamics of dating and one's own position within this dynamic; second, with regard to motives, the inclusion of other demographic variables which Gatter and Hodkinson (2016) suggest taking into further account; third, a deeper understanding of the significance, reasoning and meaning making of the use of online dating apps for the users beyond classified motives, which are operationalized in 'simple' categories like sex, love, socializing and other.

In this article, we address these perspectives and focus on the characteristics of online dating (apps) and its implications for people's dating behaviour, and their connection to a specific discourse of the self which significantly informs subjects private concept of the self (Gergen, 1991; Rose 1989). Furthermore, we point to the economic logic (Weigel, 2018) and acceleration dynamics (Rosa, 2013) inherent in mobile online dating and reflect on subjects' scopes for action and meaning making, in terms of Josephs and Valsiner (1998), within and maybe against the specific framework online dating apps provide.

The paper is organized as follows: we first, reconstruct the architecture of Tinder. Understanding how the application works helps to understand the dynamics and behaviour developed in this specific context. Second, we present the results of the recent replication of the 
Tinder Motives Scale (TMS) study. Aiming for a broader understanding of physical context and social aspects, we extended the scale by incorporating further demographic variables as level of education (milieu), gender, age and the perspective of geographical background as level of urbanization, in both regard to place of origin and place of residence. Third, we refer to more in-depth insights from a qualitative study based on 68 guided interviews, which show the using habits, complexity of functions and meaning for the users. ${ }^{1}$

\section{Tinder as Daily Practice}

\section{'Who' Is Tinder and Why Is It Important?}

The Tinder app was launched in 2012 and is today the most popular of the numerous online dating platforms. Tinder was privately founded and was purchased by the Match Group in 2017 for 1 billion US bollars. The newest estimate of the worth of Tinder just hit 10 billion US dollars. Tinder counts about 57 million users of which 10 million are active on a daily basis in 196 countries around the world. $80 \%$ of Tinder users are between 18 and 34 years old, and $62 \%$ are male, $38 \%$ female. $54 \%$ are singles, $12 \%$ are in a relationship and $30 \%$ are married and even though the app's origin is North American, only $40 \%$ of the users today reside there (Statista, 2019).

Tinder has been by now translated into 40 languages and generates 26 million matches per day. These lead to 1 million dates a week with a serious implication for the practice of relationships; in the USA, up to $16 \%$ (in 2017) of married or engaged couples actually met on Tinder (ibd.). There are other striking significant dynamics showing the impact of Tinder in everyday life, such as Tinder themed weddings (Lopez, Orenstein \& Hariri-Kia, 2019) and merchandise for so-called Tinderbabies (Kravitz, 2018).

\section{Function: How Does Tinder Work?}

A Tinder profile is easily created. The minimum requirement of information that the profile has to contain is age, location and a profile picture; normally, the user adds at least one picture, if this information is not provided, there is a generic gender-specific avatar shown instead. For this one profile picture, no further requirements are given (it could be animals, nature, a black surface). Along with the profile picture, age and gender, one has to inform the app about one's own requirements for partners regarding gender, age range (between $18^{2}$ and 100+) and physical distance with a maximum option of $160 \mathrm{~km}$.

There are several more options to design one's profile though. The user can add up to 9 pictures and for the first picture a boomerang life scene (tiny looping video sequence), a profile text with up to 500 characters, connection to Spotify, favourite music or many more pictures through the connection with Instagram, profession, educational background, employer and hometown. The free version provides 100 swipes a day to accept or dismiss suggested profiles and offers one 'super like' per day (meaning users can bypass the anonymity of likes and show before the other person decides to like or not). Users can choose to let Tinder change the order

\footnotetext{
${ }^{1}$ This enumeration does not imply a sequence of studies, which were conducted partly at the same time.

${ }^{2}$ Under 18 years old, Tinder grants access from 13 years and older, can only get in contact with others under 18 years old. 
of the pictures in order to have the most successful picture as the profile picture; this decision is based on the quantitative matching success of the pictures measured and determined by an algorithm.

User do have the option to upgrade to a 'plus' (9.99 USD) or a 'gold' (14.99 USD) version. ${ }^{3}$ In these versions, there is no limitation to swipes, the user can change the local position, one can rewind the latest swipe, there are no ads and a free boost (i.e. one's profile gets priority in one's region for $30 \mathrm{~min}$ ) per month and additional boosts can be purchased in the app. Moreover, the premium version includes five super likes per day. Tinder gold gives access to see who liked them. In fact, around half of the Tinder users spend the extra money, with users' main reason for the upgrade being the unlimited number of swipes (WeischerMedia, 2019).

Once one has created a profile the Tinder algorithm continuously offers one the profiles of possible mates regarding age range, gender and physical distance. The picture of the possible partner appears on the screen, showing beside the picture the name or nickname, age (unless it is chosen not to be shown) and parts of the text, sometimes the connection to musical tastes, or the distance depending on the details one disclosed. The user can decide whether one likes the picture or not by swiping to the right (like) or left (dislike) or give a 'super like' which requires the use of a button below the picture (limited amount). Checking further pictures, besides the profile pictures, requires an interruption in the act of swiping. One cannot see who liked oneself without deciding to give a like or not - in case both like each other, the app 'applauses' with a celebrating animation of the two profile pictures matching. Afterwards, there occurs the option to get in contact in the form of a chat environment. This means people can only get in contact with each other when they reciprocally liked one another. It is not possible to 'shop' between profiles, as once one has decided, there is no turning back and at the same time, a decision has to be made to get access to further suggestions, and even in the paid version only the last decision can be unmade. Matches are collected in the chat environment where the profile pictures of the matches are collected like small items, which can be used as a button to check the profile again or to get in contact and chat with the person, or to unmatch the profile again. This can happen to any user at any time; once one has a match, there is no secure way of keeping it; if one's profile is unmatched, it is impossible to get in contact with this person again.

By virtue of these functions, users cannot know who and how many other users see their profile. They cannot influence the algorithm other than through the boost option. However, there is no way to know who sees one and there is no control over or insights into other profiles other than the provided information.

A user has to be active and 'swiping' to get access to information and options. ${ }^{4}$

Tinder's way of functioning reminds the observer of a (virtual) ball ${ }^{5}$ where the user puts oneself on the dancefloor to be judged by unknown others and at the same time finding him- or herself most likely entertainment in looking around and judging others according to a first impression. Different from a real, analogue ball are the following characteristics:

\footnotetext{
${ }_{3}^{3}$ Please be aware that the numbers are stated in 2019 and that there occur some discount depending on age.

${ }^{4}$ Please be aware that the structure is updated on a regular basis; mostly, it is minor optimization though. This also counts for the algorithm, which pairs depending on success rate and other, publicly hidden, variables.

${ }^{5}$ We are grateful for the productive discussions with Prof. Jo Reichertz within the context of a workshop in September 2019, from which this term emerged.
} 
- the other cannot be seen while watching and also oneself is hiding until stepping forward with a like.

- the other and one's own first impression is based on one (or more) static picture(s).

- the number of potential others is much higher.

Similar to former dating strategies, online dating app users enter a kind of market putting the best version of oneself on it to attract the other. What is new, though, is that both the suggested other and the competition on one's own side is rather mysterious and unknown and that there is a dichotomy, or rather an 'all-or-nothing kind' of feedback - match or no match without a potential for progress. All this is based on a few or even one picture that has to 'present it all'. Also, the numbers are increased, at a ball, one might meet 200 people, giving a maximum of around 100 possible partners (in a heterosexual context), some of them not available, leaving one with a relatively low number of options while the average number of swipes a day is around 140. In contrast to other online dating services like online dating agencies, who made overcoming distances possible, the location bound apps go back to location-based dating.

\section{Love, Sex and What Else? Replication of the Tinder Motives Scale}

The validated Tinder Motives Scale (TMS) (Timmermans \& De Caluwe 2017) was developed based on qualitative interviews in Belgium and the USA. Conducted with 3244 participants aged between 18 and 67 ( $\mathrm{M}$ age 22.66; 64\% females), the study revealed diverse motives for usage and not only to find quick sex. The categories are ranked based on importance for participants: amusement, out of curiosity, to socialize, to find love, as an ego boost, for distraction, to improve flirting (skills), to meet people from LGBTQ community, due to pressure of social belongingness, for travel reasons, for casual sex, to forget an ex, to be cool (Timmermans \& De Caluwe, 2017).

Aiming for a deeper understanding of the app in regard to the impact of sociodemographic variables as the social context in the form of milieu, age and 'degree of urbanization' which had not been targeted by former studies, we replicated TMS in 2019 in Germany. ${ }^{6}$ For this reason, the original questionnaire was enlarged by information about the level of urbanization of actual residence and level of urbanization of the place of origin (cluster categories: residents more than 500,000; 100,000-499,000; 20,000-99,000; and 5000-19,999, less than 5000) and information to target milieu differences based on highest educational degree achieved and the educational degree of the parents.

The replication was conducted with 2651 participants, who were recruited online, through QR codes in different school forms and universities $(N=290)$ and - to get a larger number and enlarge heterogeneity of participants - through distribution via two podcasters who discuss the topic of online dating and dating and who shared the survey on their social network platforms $(N=2361){ }^{7}$ The age range of the participants was mainly $(95 \%)$ between 18 and 27 years, of them $8 \%$ male, $91 \%$ female and under $1 \%$ diverse. $30 \%$ have their actual residence in a large city (more than 500,000), $22 \%$ in cities up to 499,000 and $26 \%$ in cities up to 99,000 residents. $86 \%$ are heterosexual, $5 \%$ homosexual and $9 \%$ bisexual. $51 \%$ are single, $47 \%$ in a relationship and $2 \%$ in an open relationship. $78 \%$ hold at least an advanced school leaving certificate.

\footnotetext{
${ }^{6}$ We are grateful to Martin Förster for his valuable support in data analysis.

${ }^{7}$ We would like to thank Diana Buchholz and Taddäus Wilken who collected the data.
} 
The main results show that the participants in this study, quite similar to the original study, use Tinder mostly for reasons of curiosity, followed by entertainment, relationship seeking and sexual orientation (for the complete ranking see Table 1).

As expected, sociodemographic aspects proved to be important for some of the motifs, of which some are presented below (Table 2):

These insights come with some limitations: our study was conducted in Germany. Our sample consists of significantly more women, which also explains why we specifically did not focus on gender differences - the results must be considered mainly relevant for females so far.

Moreover, in Germany, it can be argued that due to population distribution, there occur no real 'rural' areas as the next urban area is maximum a few hours' drive away.

Furthermore, there most likely occur strong biases due to social restriction and social desirability in regard to the motive of sex and entertainment, as it might be more accepted to hide behind statements of not taking the use to serious, for example, to protect against social judgement.

There is some significance showing in the variable of milieu, which often would not consist in the beta model. This may be related to shortcomings of the measurement of milieu depending only on the highest degree of education. Thus, 'milieu' as a variable may not be sufficiently represented by educational degrees attained. Furthermore, we still have shortcomings in considering sociodemographic variables, like the number of sexual partners, religion, income and cultural background.

Nevertheless, the main results of the original study could be replicated mainly through analogy, and the inclusion of additional sociodemographic variables leads to further insights about the usage of the app. Motives vary depending on living area, educational background and gender and call for more in-depth studies on the function of tinder and online dating from subjects' perspective.

\section{Not (Only) a Game: Why Do People Use Tinder?}

As shown above, the quantitative data provides some more insights beyond stereotypical presumptions often connected with online dating apps. These results, however, call for a more holistic and in-depth understanding of the app's meaning for subjects. What is it like to be an

Table 1 Motives from the author's replication of Tinder Motives Scale

\begin{tabular}{llll}
\hline Motive & $n$ & Mean & SD \\
\hline Curiosity & 2643 & 46,963 & 12,619 \\
Pass time & 2643 & 44,989 & 13,149 \\
Relationship seeking & 2642 & 43,833 & 15,522 \\
Sexual orientation & 2643 & 39,918 & 18,593 \\
Social approval & 2642 & 37,36 & 15,441 \\
Socializing & 2642 & 36,328 & 13,281 \\
Flirting skills & 2641 & 36,164 & 12,966 \\
Distraction & 2642 & 35,809 & 17,025 \\
Sexual experience & 2643 & 32,866 & 14,54 \\
Forgetting their ex & 2643 & 30,145 & 19,209 \\
Travelling & 2642 & 26,369 & 16,157 \\
Peer pressure & 2643 & 25,302 & 14,497 \\
Belongingness & 2643 & 22,117 & 10,849 \\
\hline
\end{tabular}


Table 2 Sociodemographic variables and motives for using Tinder

\begin{tabular}{|c|c|c|}
\hline Variable & Motive & $\begin{array}{l}\text { Effect size/correlation \& } p \text { value } \\
* p<.05 / * * p<.01 / * * * p<.001\end{array}$ \\
\hline \multirow[t]{4}{*}{ Urbanization } & $\begin{array}{l}\text { Relationship seeking (increases for user from } \\
\text { cities up to } 499,000 \text { residents) }\end{array}$ & $\beta=0.1213 * * *$ \\
\hline & $\begin{array}{l}\text { Forgetting the ex (increases for user from } \\
\text { cities up to } 499,000 \text { residents) }\end{array}$ & $\beta=0.1055 * * *$ \\
\hline & $\begin{array}{l}\text { Improvement of flirting skills (increases in } \\
\text { cities above } 500,000 \text { residents) }\end{array}$ & $\beta=0.1096 * * *$ \\
\hline & $\begin{array}{l}\text { Social approval (increases in cities above } \\
500,000 \text { residents) }\end{array}$ & $\beta=0.1226 * * *$ \\
\hline \multirow[t]{2}{*}{ Relationship status } & $\begin{array}{l}\text { Forgetting the ex (increases for user being in a } \\
\text { relationship) }\end{array}$ & $\beta=0.0872 * * *$ \\
\hline & $\begin{array}{l}\text { Sexual experience (increases for user being in } \\
\text { a relationship/decreases for singles) }\end{array}$ & $\beta=0.103$ *** \\
\hline \multirow[t]{3}{*}{ Age } & Relationship seeking (increases with age) & $\beta=0.1238 * * *$ \\
\hline & Socializing (decreases with age) & $\beta=0.1115 * * *$ \\
\hline & Travelling (decreases with age) & $\beta=0.1186 * * *$ \\
\hline \multirow[t]{2}{*}{ Gender } & Sexual experience (high for male user) & $\beta=0.184 * * *$ \\
\hline & Sexual orientation (high for male user) & $\beta=0.2383 * * *$ \\
\hline \multirow[t]{2}{*}{ Sexual orientation } & Sexual experience (low for heterosexual user) & $\beta=0.1082 * * *$ \\
\hline & Sexual orientation (low for heterosexual user) & $\beta=0.1135 * * *$ \\
\hline \multirow{3}{*}{$\begin{array}{l}\text { Upper milieu (increases } \\
\text { with higher education) }\end{array}$} & Curiosity & $r=-.056 * *$ \\
\hline & Social approval & $r=-.0505 * *$ \\
\hline & Distraction & $r=-.0896 * * / \beta=-0.078 * * *$ \\
\hline $\begin{array}{l}\text { Lower milieu (increases } \\
\text { with lower education) }\end{array}$ & Relationship seeking & $r=.0517 * * / \beta=0.0463 *$ \\
\hline
\end{tabular}

unknown observer and to be observed by the unknown others him- or herself? Which needs does Tinder meet; which promises do users hear? Where does Tinder affect people's routines, their everyday life, self-perception and their perception of the other? What meaning does Tinder have for the subjects?

Therefore, we conducted 68 qualitative interviews (age range 21-42; nationality German and Danish) with former users, active users and a few participants not using but knowing of the app, for example through peers. The interviews were conducted in the years 2018 and 2019 in Germany. When conducting the interviews both formats occurred: skype, telephone and personal interviews. The interviews were recorded, contain a range of length between 10 and $35 \mathrm{~min}$ and were transcribed by the person conducting the interview. The guided interviews targeted different objectives: reasons for using the app, perceived impact on wellbeing and one's own behaviour, daily practice and usage, reasons for specific self-presentation (for instance showing a lot of skin, hiding either the body or the face, showing objects and so forth), expectations based on and assumed effects of the self-presentation, presentation of others and at last reasoning and meaning making. The interview was semi-structured following the explorative approach mostly preserving narrative impulses and leaving space for modifications following the flow of the narrative. The guide started with an open impulse following Gläser and Laudel (2010) about how oneself would describe the daily usage of the application, followed by the impulse of how one would describe feelings towards the application, during the usage, before and after. Other questions asked were as follows: Which role does Tinder play in your life? For what reason do you personally use it, how did you come to it? How is the general impact of Tinder on the society/your social surrounding? At the end of the interview, we asked the following more specifically: Is there something you like or 
dislike in particular? What would you like to change or improve? Do you have a particular experience in mind when thinking about Tinder, something particularly impactful or meaningful for you? How do you construct your own profile and what is the reason? How do you perceive others' self-presentation?

While conducting the interviews, we focused on a nonjudgemental atmosphere and (non-)verbal feedback accepting all digressions as being reasonable and meaningful (Gläser \& Laudel, 2010).

Through qualitative content analyses following Mayring (2015), we found various and complex reasons, behaviour and both social and individual references. Conducting qualitative content analysis normally follows two perspectives to work with the data, deductive category building, based on the theoretical background, and inductive category building, based strictly on the data (Mayring, 2000). For our explorative approach, we decided to only focus on inductive categories, following the strict first-person perspective of the subjects and the information coming from the data. To ensure intersubjectivity and to prevent group bias and homogeneous interpretation, we split into two teams, the two authors and two research assistants. We decided on a total of 10 interviews for the first round of building categories. Inductive categories following Mayring $(1991,2000,2015)$ occur from the data; this meant for us to read the interviews noting topics occurring. Then, these topics, namely codes, where connected to meaning, nuances and valuation which build the subcodes. These codes and subcodes are then undergoing several loops with the same interview in other sequences and contrasted or validated with other interviews, building the sufficient code tree with categories, codes and subcodes. Each team did use five interviews to build comprehensive code trees based on the information in the randomly allocated interviews. Then, we checked with one external researcher, before meeting with the other team and their results, where we discussed the interpretations. We had huge accordance within the categories, ${ }^{8}$ codes and subcodes, where any deviations were mainly due to wording or expansions by nuances - afterwards, we applied the code tree to the remaining interviews.

The analysis of the comprehensive data then revealed four main categories, each with some sub-categories (as shown in Table 3 with some selective examples) that are discussed with further quotes ${ }^{9}$ below.

\section{The Self}

This category entails the specific psychological phenomena subjects experience and struggle with when using the online dating app. Users' experiences and ways of acting are often characterized by significant ambivalences. For instance, while the general feeling towards the app is mainly positive — a 'fun tool' $(22 ; 12)$ and a 'positive way to pass time' $(31 ; 54)$ - and particularly having a match often comes with euphoric sensations, unfulfilling dates and especially being unmatched result in sadness, anger, uncertainty and self-doubt: 'it really hurts to get unmatched and I often speculate about the reason, what was not good enough?' $(18 ; 87)$. As if users try to prevent themselves from such strong emotions, they often lower their own expectations: 'really I want a baby, but Tinder is for sure the wrong place to find a partner for

\footnotetext{
${ }^{8}$ We cannot give the inter-rater accordance as an exact number, because it was not measured in a quantitative logic. It was 'huge' in the sense that the differences between the teams mainly related to wording, for instance the category 'legends' was named 'urban myths' by the other team while referring to the same contents.

${ }^{9}$ All examples from the interviews have been translated into English by the authors.
} 
Table 3 Category system with sub-categories and selective examples

\begin{tabular}{|c|c|c|}
\hline Category & Subcategory & Selective examples \\
\hline The self & $\begin{array}{l}\text { - Emotions }(1,2) \\
\text { - Profiles (own or } \\
\text { others) }(3,4) \\
\text { - Motives }(5) \\
\text { - Suction effect } \\
\quad \text { (positive/negative) } \\
\quad(6,7) \\
\text { - Coping (8) }\end{array}$ & $\begin{array}{l}\text { (1) 'It really hurts to get unmatched' }(18 ; 87) \\
\text { (2) 'everything, sex is always possible the rest is what I } \\
\text { really go for, feeling something, something special' } \\
\text { ( } 22 ; 61) \\
\text { (3) 'I chose different pictures, one showing my body type } \\
\text { and shape, one with friends to show that I have social } \\
\text { competence, one where I laugh, so one knows how I } \\
\text { look when I am having fun' ( } 9 \text {; } 137-138) \\
\text { (4) 'please no cars, no watches, no food and no pets, really } \\
\text { who is interested in stuff like that? And money, what is } \\
\text { it with men?' ( } 47 ; 90-95) \\
\text { (5) 'I hope to find a great match one day' }(47 ; 112) \\
\text { (6) 'it is euphoric' ( } 35 ; 11 / 18 \text {; } 49) \text {. } \\
\text { (7) 'I cannot stop swiping even though it feels dumb' (26; } \\
70) \\
\text { (8) 'without Tinder I would be so lonely' ( } 71 ; 18)\end{array}$ \\
\hline Daily practice and usage & $\begin{array}{l}\text { - Strategies (1) } \\
\text { - Stress (2) } \\
\text { - Investments (3) } \\
\text { - Selection criteria (4) } \\
\text { - Analogue dating (5) } \\
\text { - Availability (6) }\end{array}$ & $\begin{array}{l}\text { (1) 'I use standard texts; I develop them with friends or } \\
\text { copy paste them from role models on the internet who } \\
\text { have great success rates' }(9 ; 20-22) \\
\text { (2) 'it is such a waste of time, but I still use it a lot' ( } 18 \text {; } \\
48-49 \text { ) } \\
\text { (3) 'it is really hard work' ( } 43 ; 76) \\
\text { (4) 'I check if they like look hygienic' }(59 ; 80) \\
\text { (5) ' } 95 \% \text { is not good enough anymore, even though it's } \\
\text { stupid' ( } 34 ; 17) \\
\text { (6) 'you have to be quick, quick answers, quick to accept a } \\
\text { date, you get unmatched when you are not available } \\
\text { and responsive' }(69 ; 37)\end{array}$ \\
\hline $\begin{array}{l}\text { Legends (stereotypes, presumptions, } \\
\text { projections on the app, society or } \\
\text { individual) }\end{array}$ & $\begin{array}{l}\text { - Normalization }(1,2) \\
\text { - Inconsistencies }(3, \\
\quad 4) \\
\text { - Implicit convictions } \\
\quad(5,6)\end{array}$ & $\begin{array}{l}\text { (1) 'once it was a stigma but not today' }(32 ; 63) \\
\text { (2) 'really everybody has it, there is nobody not being on } \\
\text { Tinder' }(9 ; 104) \\
\text { (3) 'I delete it regularly (...) I always have it and use it too } \\
\text { much }(\ldots) \text { I delete it when I go to work' }(18 ; 10 \text { seq) } \\
\text { (4) 'I am looking for a partner }(\ldots) \text { I know couples from } \\
\text { Tinder }(\ldots) \text { there is only boring profiles, everybody is } \\
\text { so boring }(\ldots) \text { I hope to find the one' }(11 ; 60-87) \\
\text { (5) 'on Tinder there are many crazy dates' }(32 ; 71) \\
\text { (6) 'the app is for cheap dating, a hook up app, everybody } \\
\text { there is looking for the one thing' }(43 ; 71 \text { seq) }\end{array}$ \\
\hline $\begin{array}{l}\text { Resistance (against immanent logic of } \\
\text { action) }\end{array}$ & $\begin{array}{l}\text { - Notifications (1) } \\
\text { - Slowing down (2) } \\
\text { - Shutting } \\
\text { down/delimitation } \\
\text { (3) }\end{array}$ & $\begin{array}{l}\text { (1) 'first I was always online, then I turned off the } \\
\text { notifications, I do not want to feel stressed' }(9 ; 50 \mathrm{seq}) \\
\text { (2) 'I stop swiping when I am saddled by matches, then I } \\
\text { first process these, then I continue swiping' }(28 ; 55) \\
\text { (3) '( } \ldots \text { ) then I decide not to be online for a while' }(31 ; 72)\end{array}$ \\
\hline
\end{tabular}

this' $(18 ; 59)$, 'everybody here is really a looser and boring, but I hope to find a great match one day' $(47 ; 112)$.

This, however, is contradictory to one's motives, because looking for love or a true match is the main goal for almost everybody. Sex, affairs or fun are only the minimum target with mobile online dating until the right one emerges. To still maintain their hope users' narrations often refer to stories about happy couples who met on Tinder: 'many of my friends did find their partner or wife there' $(9 ; 44)$. To raise one's respective opportunities users work on their profiles, i.e. on their self-presentation. For this, they talk with friends about which pictures are best or even consult online tutorials or counselling with bloggers or in online forums and follow role models with 'high tinder success rates' $(2 ; 108)$ (meaning many matches). The creation then follows a reflective process of impression management 'I chose different 
pictures, one showing my body type and shape, one with friends to show that I have social competence, one where I laugh, so one knows how I look when I am having fun' (9; 137-138).

Contradictions and ambivalences are also obvious in certain - positive and negativesuction effects when using the app. Users report being really thrilled or even euphoric by the possibilities and options and having a great time on the application, but also report about second thoughts and negative effects: 'I am regretting the time investment, it is normal but dumb' $(18 ; 42)$ and 'I can't stop swiping, even though it is so meaningless and I am often disappointed' (2; 78).

Even though responses were ambivalent and contradictory, quite a few responses referred to use the application as a serious coping tool for overcoming personal crises like a divorce, loneliness and self-doubt: 'really I don't know how I would ever be re-established without Tinder after my cruel divorce, I was devastated and this really helped me and brought me back to life' $(64 ; 122)$.

\section{Daily Practice/Usage}

Users dealing with the app show how they handle the specific requirements and characteristics of mobile online dating like time pressure and countless but successively arranged dates, thereby keeping open opportunities but excluding disappointment or waste of time. Their ways of using the app reveal both an integration of and their contribution to a specific logic of acceleration and optimization.

Many users express the perceived need of being available all the time: 'If you want to be successful you have to be online several hours a day' $(71 ; 98)$, 'if I would chat with them all, I had to actually quit my job' (26; 52-53).

To keep up with the pace and not lose an opportunity, they develop on the one hand agitation and on the other hand strategies like the management of likes or matches, text messages and dates as well: 'I swipe them all to the right, very fast, like within few minutes I swipe them all right, afterwards I see who matched and then I check the profile, I don't have the time to check all profiles before deciding' (43; 13 seq). 'I use standard texts; I develop them with friends or copy paste them from role models on the internet who have great success rates' $(9 ; 20-22)$. 'I swipe and then I write with a bunch of them parallel, when I know where it goes I either add more to the parallel writing or I swipe somewhat less, to keep up with them' (9; 91 seq).

Nevertheless, perceived time pressure and the quantity of options lead to feelings of stress and fatigue: 'It is really hard work to keep up with the chatting' $(39 ; 77 / 26 ; 95)$, 'I check several times a day, even though I hate it, also when being out and about, because it is necessary' $(6 ; 101)$, 'if you don't respond within minutes the match is gone' (71; 57).

To reduce such stress users try to control their investment of time, money and effort, sometimes to an extent, that even contradicts the particularity of the dating context:

'I only meet with women directly located in the neighborhood and I only take them with me to do stuff I would do anyhow, like going for a run or shoe shopping, that way I don't invest and I won't be disappointed so much, I learned that from tinder experience, keep the effort as low as possible' (61; 52-54).

Furthermore, users implement numerous selection and ranking criteria to reduce the amount of time necessary to check on others profiles: 'I don't know what would be a good profile text, I never check' $(9 ; 153)$. When selecting matches, there occur a large amount of hygiene 
arguments that could possibly be a translation to milieu: 'I check if they like look hygienic' $(59 ; 80)$ 'I often feel disgust when looking at the dirty ones' $(61 ; 129)$.

The logic of optimization is then transferred to the analogue date, too, which has to be perfect: ' $95 \%$ is not good enough anymore, even though it's stupid' $(34 ; 17)$. If a face-to-face contact is not immediately perfect the online dating wheel continues to spin: 'I am stressed if there might be someone better just around the corner' $(61 ; 34)$, 'I swipe while being on a date on the toilet' $(11 ; 52)$, 'it is the procedure, short writing, quick dating and then back on track' $(34 ; 50-51)$.

\section{Legends}

For many users, mobile online dating is strongly connected with often inconsistent or rather ambivalent generalizations, stereotypes and prejudices about the app itself, (other) people who are using it and for example gender.

Obviously, although widely used and popular, online dating is still far from being an activity considered 'normal' among its users. By emphasizing exactly this 'normality', users acknowledge at the same time its particularity, performing a normalization 'once it was a stigma but not today' $(32 ; 63)$, 'I held it for myself once but today I admit it, if someone asks' $(31 ; 135)$, '...there is nobody not being on Tinder' $(9 ; 104)$.

Others express emotional distress shown both in their practice and their ambivalent attitude towards the app: 'I only use it sporadically, I often delete the app on my phone (...) I delete it regularly (...) I always have it and use it too much (...) I delete it when I go to work' $(18 ; 10$ seq \& 42-43) (this user was installing and uninstalling the app). Others show a pejorative attitude towards the use: 'it is permanent nonsense (...) it is nothing but a blunt game' $(26 ; 52)$ (this interviewee still expressed the wish to find 'the one' there).

Perhaps, such ambivalences are partly due to a certain reputation often ascribed especially to Tinder as a fun tool or hook up app: 'when you only look for a relationship it is the wrong app' $(3 ; 74)$. In contrast and as if to contradict this reputation, many narrations entail legends about the possibility to find one's true love via Tinder: 'Everybody knows one happy couple from Tinder' $(64 ; 156)$, 'my friends did find their wife there' $(9 ; 110)$.

Furthermore, many users express generalization about other users like 'I think there are many awesome people on Tinder' $(34 ; 51)$, 'everybody is so boring on Tinder' $(11 ; 60-87)$. Many stereotypes and prejudices are connected to gender: 'everybody looks for sex there, it's obvious, even when women write they are looking for a mate' $(43 ; 59)$, 'guys are all desperate for a relationship' (11;40-41), 'I don't think highly of women having profiles there, you don't really want a girlfriend behaving like this' $(5 ; 39)$.

Moreover, users apply social and obviously moral rules of behaviour that they consider to be valid, for instance in terms of honesty: 'It is ok to lie, but only regarding for instance age, not body shape or haircut, minor polishing is acceptable, everybody agrees on that' $(9 ; 134)$.

\section{Resistance}

Within the many aforementioned contradictions and ambivalences, rather few moments or periods of resistance against the immanent logic of acceleration and optimization occur.

Resistive strategies are, first, directed at one's own usage, thereby reducing pressure and stress: 'there is a usage evolution, in the beginning I was online all the time even at work, now I block the notifications, so I am less intrigued to be online all the time (...) I stop swiping 
when I am saddled by matches, then I first process these, then I continue swiping' (28; 55), 'I felt really stressed, so I reduced the usage significantly' $(5 ; 112)$.

Second, users try to protect the self by maintaining self-esteem and self-value: 'I have a profile but I don't show my face, this way I can protect myself' $(47 ; 83)$, 'I don't show my face, so the unmatching is easier to cope with' $(73 ; 101)$. In the very effort of self-protection, others behave contrary to the ordinary: 'I make every date really special, I try to do that by meeting in expensive restaurants, dressing all up and letting possible partners drive a long distance to get to me, that way everything means more and is more serious and exciting' (17; 103-105).

Third, resistive strategies are even employed to care for the (unknown) other: 'I check all profiles carefully, I don't want the little fat girls to be hurt by me unmatching right after the match, I do that because others told me how they are hurt from being unmatched' $(32 ; 21-22)$. As a result of feedback and reflection on the impact of the app, other users even changed their behaviour to the extent that they stopped using Tinder: 'I stopped because my friends told me I became really tough in my behavior, like unmatching in real life, I became an asshole' (14; 29-30).

\section{Discussion: Prospects and Pitfalls of Online Dating}

From our view, these complex impacts on the daily practice and the self resulting from an app specifically created to get in contact with others in a dating-like context can be discussed from different theoretical perspectives.

Following Hartmut Rosa (2005, 2013), mobile online dating platforms like Tinder seem to be paradigmatic for the different kinds of accelerations in the following ways: When speeding up dating via digital tools and mobile devices, online dating apps represent technological acceleration. The permanent appearing and disappearing of profiles and constant modifications of one's own profile reduces the half-life of information and thus signifies the acceleration of social change. Checking partner suggestions passively as they are received, making decisions about acceptance or refusal within seconds or keeping one's own profile up-to-date and doing all this while actually doing something else (like attending a lecture, on the toilet, cooking or watching a film) indicates acceleration of the pace of daily life and the acceleration also regards the dating itself, as the single date loses importance and value as the next one is just around the corner. This makes the process of not getting a second date less threatening, while at the same time accelerates the dating market, as any detail that does not fit leads to dismissal (Finkel et al., 2012). Tinder's accelerated logic inscribes itself in users' daily routines and practices, in their social encounters and their self-related thoughts and judgements. Users experience the pressure to constantly be available and active, to decide quickly and to optimize their own profile receptively. On the other hand, while using the app 'in-between', 'instead of' or 'parallel to' other activities, subjects contribute to the accelerated logic themselves. This view is reinforced by the fact that many users actually pay to be able to swipe even more.

Alongside acceleration, the inherent economic logic of mobile online dating, with users trying to control chance, disappointment or time through preselection, further increases pressure on subjects according to Moira Weigel (2018). To be successful and effective on the dating, market users shape and optimize their profiles constantly (see also Ward, 2016). Again, they contribute to rather than undermining this logic for instance by developing 
streamlined communication strategies like standard text messages for all matches or managing matches like the exclusion of certain suggestions.

Despite its inherent logics, the app itself does not prescribe or determine users' behaviour. Hypothetically, they could establish practices opposite to the immediate app's logic such as creating highly differentiated, personal profiles with a certain degree of disclosure or individuality and then study each suggested match carefully, deciding on one or a few suggested people a day before going into long conversations and deciding whether or not to meet in the analogue world. Although moral regrets and critical reflections of one's own behaviour might implicate a longing for such a setting — for improving quality instead of quantity — users rarely use Tinder in this alternative way.

Tinder seems to represent (at least) two contradictory faces - the face of stress and harmful impact on the self and one's behaviour and the face of a tool overcoming social barriers, being perceived as a coping strategy to overcome personal challenges. These two faces can often be found in a kind of tense coexistence within the user. For instance, he or she might suffer the pressure of being available all the time and at the same time likes to get to know new people or the user longs for the excitement of likes and matches but is severely hurt when being unmatched his- or herself or, as a third example, the user hopes to find their one and only partner on Tinder but simultaneously devaluates other users as 'boring' or 'desperate'. How people handle these tensions can be understood from the perspective of circumvention strategies in terms of Josephs and Valsiner (1998). Circumvention strategies by that users e.g. overrule their doubt to find a real love on Tinder by telling oneself 'you never know' enable the subject to navigate through a highly ambiguous everyday practice of life. Even while using this perspective for a broader understanding of the ambiguity of the narratives, the sufficient psychosomatic analysis of the autodialogical aspects is still to be carried out in future research.

Putting oneself on a kind of market, adopting and even enforcing highly accelerated social routines, changing and shaping one's self-presentation according to assumed or perceived social norms and in striving for success (in the form of likes, matches or dates) and at the same time attributing failure to one's own ineffectiveness or unattractiveness point to important features of the discourse of the (private) self, which Kenneth Gergen (1991) and Nikolas Rose (1989) described as characteristic for liberal, Western (post)modern societies. In these societies, people are addressed and understand themselves as autonomous and free individuals who embody agency, traits, emotions and morality as inner qualities and freely negotiate chances and choices. Through this, responsibility for conducting and controlling activity, behaviour and affect, for success and failure, has been shifted onto the individual as well. Failure, then, is not due to social constraints or imbalance of power but to one's own inabilities. Being responsible for one's own life and destiny initiates competition between individuals about the best social positions and thereby the need for optimization either on the surface (impression management) or beyond for instance through counselling or therapy.

The way Tinder works and users' ways of using the app corresponds to this discourse of the self. Often implicit rules of self-presentation, especially in a dating context, are reinforced by the function of the app as it rewards users for making themselves likable. Likeability in this context can only be obtained by shaping one's profile or by even paying money to increase visibility. Making quick decisions and being permanently available further increases one's chances of likes and matches and to be quicker and more accessible than others gives an advantage in the dating competition. Comparing one's likes, matches and dates with friends or colleagues enhances this competition and might lead to further profile optimization. 
Taking part in this competition often leads to inherent contradictions and tensions between the desire to find a truly fitting match (and thereby be as honest as possible in order not be rejected when meeting face to face) and a streamlined self-presentation in terms of market conformity, between discomfort or moral regrets and (mis)judging others, or between wanting a 'real' match and many matches for self-affirmation at the same time.

Although often referred to as 'just a game', these activities are highly significant for the subject's self, i.e. self-related thoughts and judgements (Gergen, 1991; Harter, 2012, James, 1892). Tinder users constantly get dichotomous (like or dislike) feedback about their self(presentation) which is highly important for their self-consciousness and self-esteem. Nevertheless, in contrast to analogue encounters, this feedback from virtual, unknown others is only based on a small set of information and all-or-nothing communication: one will never know why one was rejected and actual of whom. Subjects can in most cases - based on the singular, dichotomous information 'unmatch' - only speculate about the reasons thereby drawing again on implicit norms and rules of a 'good' self-presentation or more generally a successful self. Subjects' experiences of stress and harm when using mobile online dating apps show that they hold themselves responsible, following a liberalistic logic of the self and by that relocating the responsibility into themselves; this points to the seriousness of this 'game', a game that is thrilling but also puts the self at stake.

\section{Conclusions and Outlook}

Picture-based mobile online dating as provided by Tinder is a complex social context that often severely influences users' daily lives and activities but at the same time is shaped itself by the way users behave within and relate to this context.

Beyond generalizations and stereotypes regarding both the application (for instance as 'superfluous' or 'for fun') and its users (for instance as 'sex seeking' or 'desperate'), mobile online dating entails serious and multifaceted implications on subjects' thoughts, motives, emotions, self-esteem and well-being. Hereby, subjects find themselves in a tension between individuality and normativity as expressed in the ambivalences and inconsistencies concerning one's self-presentation (social acceptability vs. intimate needs and desires) and online dating in general (incredibly joyful vs. potentially harmful). Moreover, through mobile online dating, users position themselves in society, thereby relying on implicit social norms with regard to gender and class but also to self-presentation and dating behaviour.

The specific architecture and functioning of Tinder facilitate but do not prescribe an accelerated and economic logic of use. This logic corresponds to the respective mode of liberal, Western societies and, within these, to a specific discourse of the self that celebrates the self-responsible, competing individual. An accelerated and competition-driven way of use often leads to pressure and a subsequent implementation of strategies to reduce it, but quite rarely to resistance in the form of changing using habits. Furthermore, there seem to be restrictive normative rules that are followed, even when having second thoughts. Through mobile online dating, practices of making contact and approaches as well as self-related practices are relocated into a specific digital space which in turn affects the analogue space, too. Thus, Tinder can be understood as a dispositive according to Foucault (1978) that influences both users' subjectivity and social practices.

To grasp more of this obvious complexity of mobile online dating and to get access to an in-depth understanding of subjects' self-conception and self-positioning, we took a kind of a 
step back and started with reconstructive analyses of both narrations and profile pictures relocating the focus from 'what' is said or shown to 'how' it is done. Furthermore, based on understanding Tinder as a dispositive, we have started to analyze the application as such.

Acknowledgements Open Access funding provided by Projekt DEAL.

Open Access This article is licensed under a Creative Commons Attribution 4.0 International License, which permits use, sharing, adaptation, distribution and reproduction in any medium or format, as long as you give appropriate credit to the original author(s) and the source, provide a link to the Creative Commons licence, and indicate if changes were made. The images or other third party material in this article are included in the article's Creative Commons licence, unless indicated otherwise in a credit line to the material. If material is not included in the article's Creative Commons licence and your intended use is not permitted by statutory regulation or exceeds the permitted use, you will need to obtain permission directly from the copyright holder. To view a copy of this licence, visit http://creativecommons.org/licenses/by/4.0/.

\section{References}

Carpenter, C. J., \& McEwan, B. (2016). The players of micro-dating: individual and gender differences in goal orientations toward micro-dating apps. First monday, 21, 5. https://doi.org/10.5210/fm.v21i5.6187 [23.11.2019].

Duguay, S. (2015). Dressing up Tinderella: interrogating authenticity claims on the mobile dating app Tinder. Information, Communication \& Society, 20, 3, S. 351-3, S. 367. https://doi.org/10.1080/1369118 X.2016.1168471[23.11.2019].

Foucault, Michel (1978). Dispositive der Macht. Michel Foucault über Sexualität, Wissen und Wahrheit. Berlin: Merve Verlag.

Fitzpatrick, Colin, Birnholtz, Jeremy \& Jed R. Brubaker, Jed R. (2015). Social and personal disclosure in a location-based real time dating app. Kauai: 2015 48th Hawaii International Conference on System Sciences, S. 1983-1992.

Finkel, E. J., Eastwick, P. W., Karney, B. R., Reis, H. T., \& Sprecher, S. (2012). Online dating: a critical analysis from the perspective of psychological science. Psychological Science in the Public Interest, 13(1), 3-66. https://doi.org/10.1177/1529100612436522.

Gatter, Karoline, Hodkinson, Kathleen, Monika Kolle (Reviewing editor) (2016). On the differences between Tinder $^{\mathrm{TM}}$ versus online dating agencies: questioning a myth. An exploratory study. Cogent Psycology, 3:1, DOI: https://doi.org/10.1080/23311908.2016.1162414 [23.11.2019].

Gläser, J., \& Laudel, G. (2010). Experteninterviews und qualitative Inhaltsanalyse. Wiesbaden: VS Verlag für Sozialwissenschaften.

Gergen, K. (1991). The saturated self: dilemmas of identity in contemporary life. New York: Basic Books.

Hance, M. A., Blackhart, G., \& Dew, M. (2018). Free to be me: the relationship between the true self, rejection sensitivity, and use of online dating sites. The Journal of Social Psychology, 158, 4, S. 421-4, S. 429. https://doi.org/10.1080/00224545.2017.1389684 [23.11.2019].

Harter, S. (2012). The construction of the self. Developmental and sociocultural foundations. New York: Guilford Press.

James, William (1961/orig. 1892). Psychology: the briefer course. New York: Harper Torchbooks.

Josephs, I.,. E., \& Valsiner, J. (1998). How does autodialogue work? Miracles of meaning maintenance and circumvention strategies. Social Psychology Quarterly, 61(1), 68-83.

Kravitz, Jamie (2018). 5 Tinder-themed wedding photos that perfectly honor how the couple met. Verfügbar unter: https://www.elitedaily.com/p/5-tinder-themed wedding-photos-that-perfectly-honor-how-the-couplemet-11955414 [23.11.2019].

Lopez, Veronica, Orenstein, Hannah \& Hariri-Kia, Iman (2019). This couple met on HER \& bonded over their names. Verfügbar unter: https://www.elitedaily.com/p/5-tinder-themedwedding-photos-that-perfectly-honor how-the-couple-met-11955414 [23.11.2019].

Mayring, P. (1991). Qualitative Inhaltsanalyse. In U. Flick, E. V. Kardoff, H. Keupp, L. V. Rosenstiel, \& S. Wolff (Eds.), Handbuch qualitative Forschung: Grundlagen, Konzepte, Methoden und Anwendungen (pp. 209-213). München: Beltz - Psychologie Verl. Union.

Mayring, Philipp (2000). Content analysis. Forum: Qualitative Social Research. 1(2). DOI: https://doi. org/10.17169/fqs-1.2.1089 [10.2.2020]. 
Mayring, P. (2015). Qualitative Inhaltsanalyse. Grundlagen und Techniken. Beltz: Weinheim.

Rosa, H. (2005). Beschleunigung. Die Veränderung der Zeitstrukturen in der Moderne. Suhrkamp: Frankfurt am Main.

Rosa, H. (2013). Beschleunigung und Entfremdung. Entwürfe einer kritischen Theorie spätmoderner Zeitlichkeit. Suhrkamp: Frankfurt am Main.

Rose, N. (1989). Governing the soul. The shaping of the private self. London: Free Association Books.

Sedgewick, Jennifer R., Flath, \& Elias Lorin J. (2017). Presenting your best self(ie): the influence of gender on vertical orientation of selfies on Tinder. Frontiers in Psychology, 8:604, DOI: https://doi.org/10.3389 /fpsyg.2017.00604 [23.11.2019].

Sevi, Barıș (2019). The dark side of Tinder: the dark triad of personality as correlates of Tinder use. Journal of Individual Differences. DOI: https://doi.org/10.1027/16140001/a000297 [24.11.2019].

Sevi, B., Aral, T., \& Eskenazi, T. (2017). Exploring the hook-up app: low sexual disgust and high sociosexuality predict motivation to use Tinder for casual sex. Personality and Individual Differences. https://doi. org/10.1016/j.paid.2017.04.053.

Smith, Aaron \& Duggan, Maeve (2013). Onlinedating \& Relationships. Verfügbar unter: https://core.ac. uk/download/pdf/71363110.pdf [23.11.2019].

Statistica (2019): 4,7 Millionen zahlen für Tinder. Verfügbar unter: https://de.statista.com/infografik/16037 /zahlende-nutzer-von-tinder/ [20.12.2019].

Strubel, Jesscia \& Petrie, Trent (2017). Love me Tinder: body image and psychosocial functioning among men and women. Body Image, 21, S.34-S.38, DOI: https://doi.org/10.1016/j.bodyim.2017.02.006 [24.11.2019].

Sumter, S., Vandenbosch, L., \& Ligtenberg, L. (2016). Love me Tinder: untangling emerging adults' motivations for using the dating application Tinder. Telematics and Informatics, 34. https://doi.org/10.1016/j. tele.2016.04.009.

Timmermans, E., \& De Caluwé, E. (2017). Development and validation of the Tinder Motives Scale (TMS). Computers in Human Behavior, 70, 341-350.

Tyson, G., Perta, V. C., Haddadi, H., \& Seto, M. C. (2016). A first look at user activity on Tinder. Computer Science. S., 461-466. https://doi.org/10.1109/ASONAM.2016.7752275.

Ward, J. (2016). Swiping, matching, chatting self-presentation and self disclosure on mobile dating apps. Human IT, 13(2), 81-95.

Ward, Janelle (2017) What are you doing on Tinder? Impression management on a matchmaking mobile app, Communications Society, 20:11, S. 1644-11, S. 1659, DOI: https://doi.org/10.1080/1369118 X.2016.1252412 [23.11.2019].

Weigel, Moira (2018): Dating. Eine Kulturgeschichte. 1. Auflage. München: btb Verlag.

Weischer-Media (2019). 4,1 Millionen zahlende Tinder-Nutzer sorgen für Umsatzplus. Verfügbar unter: https://weischer.media/de/de/trends-und innovationen/blickwinkel/41-millionen-zahlende-tinder-nutzersorgen-fuer umsatzplus/ [23.11.2019].

Publisher's Note Springer Nature remains neutral with regard to jurisdictional claims in published maps and institutional affiliations. 